\title{
Portuguese Nephrology: We can be greener
}

\author{
Diogo Francisco, Ivo Laranjinha \\ Serviço de Nefrologia e Transplantação Renal do Hospital de Santa Cruz, Centro Hospitalar Lisboa Ocidental
}

\section{INTRODUCTION}

Healthcare facilities are among the greatest contributors to resource consumption and waste generation. The average carbon footprint of the European Union's (EU) healthcare systems is 249 $\mathrm{MtCO}_{2} \mathrm{e}$. In the EU, $75 \%$ of healthcare-related ecological footprint relates to the healthcare's supply chain. The Portuguese healthcarerelated carbon footprint is $4.8 \%$ of total national emissions, which is above the world average $-4.4 \%^{1}$. Yet several studies have demonstrated that a bidirectional causal relationship exists between kidney disease incidence and climate change $\mathrm{e}^{2-5}$.

Internationally, there is an increasing awareness of the ecological impact of nephrology and a claim for sustainable practices ${ }^{6,7}$. In the UK, a Sustainable Healthcare Group was founded within the National Health Service (NHS). The Green Nephrology Initiative - one of its branches - promotes investigation, financing and implementation of ecological solutions. It has brought both financial savings and ecological benefits 8,9 .

There are no precise data on the contribution of kidney care to the environmental impact of healthcare systems, but it is likely to be high. It is estimated that up to $11 \%$ of the Portuguese population have chronic kidney disease (CKD) ${ }^{10}$. In 2019, there were 20,640 patients with CKD stage 5D/T in Portugal - 12,523 under hemodialysis, 852 under peritoneal dialysis (PD) and 7,265 transplant patients with a functioning graft ${ }^{11}$.

We present a review on the environmental impact of different nephrology areas, with ecological measures and our center's experience.

\section{GENERAL APPROACH / NEPHROLOGY}

\section{Medical visits and drug therapy}

The ecological impact of nephrology clinic relates mostly to drugs' production and distribution cycle and patient transportation. Producing and distributing medical drugs has a significant, albeit not quantified, ecological impact. Measures against drug hoarding and waste should be taken by every patient and clinician, in close collaboration with the community and hospital pharmacies ${ }^{12}$.

A collaborative program with primary care facilities allows most patients to be followed in the community units by a general practitioner until later stages of CKD. Bringing kidney care out of the hospitals reduces travels, and telehealth is a tool yet to be optimized.
Patient education and autonomy play a critical role in preventing the need for medical care ${ }^{13}$.

\section{Ward}

Admission to a medical ward implies a non-negligible ecological impact, namely energy and waste related to the functioning of the hospital. Every department should be aware of its expenses related to lighting, heating, feeding, cleaning and laundry. Setting all computers to shut down or hibernate when not in use, setting two-sided printing in all printers. Computerization and paperless clinical files should be a priority. Simple domestic environment-friendly measures can minimize waste and resource consumption in hospitals, such as turning off air-conditioning and lighting when not in use. Thermal insulation is a structural energy and moneysaving investment. Architectural optimization of natural light source and usage of energy efficient lighting and automatic switch controls (movement sensors) are tools for lighting-related energy savings. Choosing reusable, recyclable and recycled materials minimizes waste ${ }^{14}$.

\section{Waste}

Waste generated in a renal unit is either clinical or nonclinical. Nonclinical waste consists of packaging material, office paper, leftover food, etc., which can be treated as it would be at home. Appropriate segregation of recyclable materials is a key step in wisely managing waste from renal units ${ }^{14}$.

Clinical waste from healthcare facilities includes pharmaceutical waste, sharps and infectious waste, among others ${ }^{15}$. The financial cost of hazardous waste disposal is high, reaching for instance $€ 16$ per hemodialysis session ${ }^{16}$. Even though incineration remains the cornerstone for treating contaminated clinical waste and sharps, there are more eco-friendly alternatives, such as autoclaving ${ }^{17}$.

Biopsy performance and catheter placements are among the most waste-generating procedures, generating mostly contaminated plastic.

Recycling of packaging material and substituting hazardous materials help minimize environmental impact of kidney care-related waste ${ }^{17}$.

Dealing with transmissible diseases, namely during the COVID-19 pandemic, entails a high burden in managing contaminated waste consisting of personal protective equipment (PPE). Simple organization and communication measures can be taken to minimize PPE usage - for example, synchronizing blood draws with drug administration avoids unnecessary entries in contaminated areas. 


\section{RENAL REPLACEMENT THERAPIES}

\section{Hemodialysis}

Hemodialysis machines, water treatment and distribution systems require large amounts of energy and water. Thrice weekly in-center chronic hemodialysis implies non-calculated emissions related to patient transportation. This poses a severe environmental burden. Eco-dialysis practices are easy, simple and commonly cost-neutral or long-term cost saving ${ }^{18}$.

\section{Water}

A 4-hour hemodialysis treatment session requires $350 \mathrm{~L}$ of water (unpublished data). Prolonged droughts may increase water prices - and hence the cost of hemodialysis -, in severe cases making it impossible to perform.

A variable amount of water presented to a reverse osmosis (RO) machine is sent to drain as RO reject water (RW). RW is considered unfit for human intake ${ }^{19}$. Despite not fitting the criteria for potable water due to a complete lack of chlorine, RW poses no infectious risk $^{20}$. Reuse of RW from RO machines is gaining interest ${ }^{21}$, as it may be stored in tanks and used in gardening, laundry, cleaning, toilet flushes and sterilization of medical material, both at home or in hemodialysis centers ${ }^{22}$. Some experiences have shown full return of initial investment (tank and plumbing) in few years ${ }^{23}$ and savings of $€ 11,059$ $(£ 10,000)$ per year (in a center with 45 hemodialysis machines) ${ }^{24}$, making ecological concerns economically rational.

Loop water distribution systems have become mainstream in Portugal and allow recirculation of treated water, therefore saving water and energy. Installation of automatic flow regulators that adapt the water flow to the distribution loop to the hemodialysis machine's needs has proven to reduce water waste 20 .

Decreasing dialysate flow rate (Qd) from $500-800 \mathrm{ml} / \mathrm{min}$ to 400 $500 \mathrm{~mL} / \mathrm{min}$ is not associated with significant reduction of dialysis efficacy ${ }^{25,26}$. The evidence so far shows that reducing it closer to 400 $\mathrm{mL} / \mathrm{min}$ may be feasible, especially in patients with a body weight of less than $70 \mathrm{~kg}^{19}$. This could represent saving up to $100 \mathrm{~L}$ of water per hemodialysis session.

Sorbent dialysis is regaining interest as a means of saving water for hemodialysis ${ }^{27}$. The REDY system requires only about $6 \mathrm{~L}$ of untreated water per treatment. The effluent recirculates through a sorbent column allowing effluent regeneration. The wearable artificial kidney - based on this dialysate regenerating sorbent technology - is currently under technical redesign ${ }^{28}$. Wearable and implantable artificial kidney technology has undergone only small-scale clinical trials in humans. There are currently no such devices that provide a feasible alternative to standard PD or hemodialysis. When in place, these will generate far less nonbiodegradable plastics and spent dialysate (29, 30), while being a suitable clinical alternative.

Reuse of dialysate effluent of hemodialysis for agriculture was studied in Morocco, a region that frequently experiences periods of water scarcity ${ }^{31}$. Dialysate effluent, a high conductivity water, was treated with RO - a treatment that proved to be more efficient and cheaper than seawater desalination. Nevertheless, dialysate effluent reuse has some problems, such as potential transmission of infections and high concentrations of substances such as ammonium, phosphates, sulphates and other nitrous compounds 32 .

\section{Waste}

The Portuguese Directorate-General of Health recommends that all waste generated in a hemodialysis facility should be incinerated (or equivalent) ${ }^{33}$. Solid waste includes plastics from the dialyser, blood tubing sets, syringes and concentrate containers, metals from needles, and glass from pharmaceutical drugs. Less than one third of nonhazardous waste is potentially recyclable - use of different types of plastic, glues, inks and labels prevents the remaining materials from being recycled ${ }^{16}$.

Central delivery systems that provide concentrated dialysate acid reduce dialysate and plastic waste derived from dialysate bags ${ }^{12}$, as well as the need for its transportation. On the other hand, locally preparing and centrally delivering liquid bicarbonate makes it susceptible to microbiological contamination processes and is therefore not advised $^{34}$.

Although dialyzer reuse seemed an ecologically attractive solution, it is no longer a common practice in Europe mainly because of potential transmission of infections and decreased dialyzer performance. Issues related to dialyzer sterilization have a non-negligible environmental impact $^{12,26}$.

At our unit (which has no central delivery of acid system), each patient generates $546 \mathrm{~kg}$ of waste yearly, $37 \%$ of which is plastic (unpublished data) (Table 1).

\section{Energy and carbon emissions}

Carbon footprint - defined as the sum of greenhouse gas emissions released by an organization, product or service - expressed as carbon dioxide equivalents (CO2e), has been calculated to be 3.8-10.2 ton

\section{$\underline{\text { Table } 1}$}

\begin{tabular}{|c|c|c|c|}
\hline \multirow{2}{*}{$\begin{array}{c}\text { Ecological impact } \\
\text { of dialysis }\end{array}$} & \multicolumn{2}{|c|}{ Peritoneal dialysis } & \multirow{2}{*}{ Hemodialysis } \\
\hline & APD & CAPD & \\
\hline Water & \multicolumn{2}{|c|}{ Unknown } & 350L/treatment \\
\hline Waste & $\begin{array}{c}671-739 \mathrm{Kg} / \text { year/patient } \\
\text { (60-72\% plastic) }\end{array}$ & $\begin{array}{c}533-613 \mathrm{Kg} / \text { year} / \text { patient } \\
\text { (35-60\% plastic) }\end{array}$ & $\begin{array}{c}546 \mathrm{Kg} / \text { year} / \text { patient } \\
\text { (37\% plastic) }\end{array}$ \\
\hline Energy & \multicolumn{2}{|c|}{ Unknown } & 9-10kWh/treatment \\
\hline
\end{tabular}


$\mathrm{CO} 2 /$ year/patient in hemodialysis ${ }^{35}$. A standard hemodialysis treatment session consumes 9-10 kWh (unpublished data).

Usage of renewable energy sources has demonstrated to be economically attractive and ecologically wise. Portugal benefits from high solar radiation availability with a low annual variability, especially in the south, which makes solar energy a rational investment. An Australian pilot study has shown how installing solar panels may produce a neutral net power consumption and how the system may even become profitable 36,37 .

Dialysate heating consumes energy. As an alternative, heat exchangers - a device that can be attached to some hemodialysis machines - transfer energy from dialysis effluent to the incoming dialysate before it enters the heater. Annual savings from heat exchanger installation were $€ 53$ ( $£ 48.05$ ) per machine, with full return of investment achieved after four years. Thereafter, annual savings of $€ 2,763$ ( $£ 2,498.60)$ were anticipated for the 52-machine hemodialysis unit ${ }^{38}$.

Home dialysis is anecdotal in Portugal. It has shown modest ecological benefits ( 7.2 ton $\mathrm{CO} 2$ per patient per year $)^{35,39}$. As the frequency of treatments is the main factor influencing the carbon footprint of hemodialysis, rising the prevalence of home hemodialysis - dialyzing more frequently and for longer - would increase the emissions associated with hemodialysis programs despite reductions in travels ${ }^{13}$.

\section{Peritoneal Dialysis}

In Portugal, around $6 \%$ of patients on dialysis are under peritoneal dialysis ${ }^{11}$, making the ecological impact of this type of treatment less significant than hemodialysis. The real carbon footprint of PD is, however, unknown. Peritoneal dialysis requires 6-12L of PD solution daily, yet, there is no information available about the amount of water required to produce PD solutions nor about the carbon footprint of transporting PD solution from the point of manufacture to the point of care ${ }^{35}$. In addition, producing one kilogram of plastic requires $180 \mathrm{~L}$ of water ${ }^{22}$.

Telehealth and telemonitoring are becoming increasingly important in PD patients' care. Some technologies such as Claria @ transfer information on peritoneal dialysis exchanges over the internet onto a proper clinical software, allowing physicians and nurses to solve several problems remotely.

Plastic consumption is greater in PD than hemodialysis. However, Biofine $($ is a PVC-free polymer used in the majority of Fresenius Medical Care ${ }^{\circledR}$ products for peritoneal dialysis, which provides an ecological alternative to conventional plastic that requires less energy for production and does not release hydrochloric acid upon incineration. Some plastic reduction alternatives such as the U-drain ( ) systems have been put in place. This requires installation of drainage tubing from a cycler to allow direct drainage of peritoneal effluent into the sewerage system (some patients in our PD Unit use homemade alternatives to this system).

At our unit the weight of total waste generated by each patient on continuous ambulatory peritoneal dialysis (CAPD) varies between 533-613
Kg yearly (of which $35-60 \%$ is plastic). On automated peritoneal dialysis (APD), this grows to $671-739$ Kg yearly (60-72\% plastic) (unpublished data) - this variation depends on the number of exchanges and on the brand of PD solution used. Other centers found similar values ${ }^{17}$. (Table 1)

\section{Kidney transplantation}

Kidney transplantation is by far the most ecological treatment for CKD stage 5D/T. Its environmental impact relates mostly to initial hospital admission and kidney transplantation surgery, as well as the use of immunosuppressive drugs. In Portugal, however, follow-up of kidney transplant recipients is the responsibility of the kidney transplant center as long as the graft is functioning. This has a heavy ecological burden in terms of patient transportation.

Remote consultation has shown to be an acceptable carbon-saving alternative for follow-up of renal transplant recipients ${ }^{40}$. At our unit, and since the COVID-19 pandemic started, an integrated telehealth programme has been extended. Remote consultations take place with either the patient or the local nephrology assistant alone, or both. Agreements with local laboratories allow patients to perform blood and urine analysis in their local communities and results are automatically sent to our center. Immunossupressants are sent by mail to the patient's address.

We also believe follow-up of post-transplant patients by their local nephrology department is a suitable alternative, unless there is other clinical indication for follow-up in a transplant center.

\section{STRATEGIES TO REDUCE DIALYSIS BURDEN}

No therapeutic decision should be made based on ecological concerns. The priorities of treatment must be clinical outcomes and patient quality of life. However, reducing the environmental burden of dialysis, whenever clinically suitable, may be an ecological solution, as dialysis is a resource-consuming technique. In such cases, the argument for protecting the environment adds to clinical benefits.

Well-established conservative therapy programs for end-stage kidney disease - lacking in Portugal - may offer a structured option for some patients. Optimized kidney selection in deceased- and livingdonor transplant may bring more patients out of dialysis. CKD prevention reduces its ecological and economical burden. Reducing social and economical risk factors for CKD should be a priority ${ }^{12}$.

\section{THE FUTURE}

Reducing the ecological impact of kidney care can be performed both locally or nationally, as well as in dialogue with industry. Health policy and regulations contribute strongly to this balance (Table 2).

Locally, each nephrology department should define a Green Person, responsible for drawing up and implementing green projects, taking into account the specificities of each department. Collecting data on electricity consumption, water usage and waste production should 


\begin{tabular}{l|l}
\multicolumn{1}{c}{ General/National measures } & \multicolumn{1}{c}{ Local measures } \\
\hline \multicolumn{1}{c|}{ LKD prevention programs; } & - Define a Green Person; \\
\hline - National guidelines with ecological recommendations and targets for Dialysis Units; & - Computerization and paperless clinical files; \\
- Implement conservative therapy programs; & - Optimize heating/lighting energy use; \\
- Optimized deceased- and living donor kidney transplantation programs; & - Choosing reusable, recyclable and recycled materials when signing contracts with the \\
- Telehealth, telemonitoring and remote specialist consulting; & industry; \\
- Patient autonomy and health education; & $\begin{array}{l}\text { Choose autoclaving (or other ecologic alternatives to incineration) for treating con- } \\
\text { - Follow-up of post-transplant patients at their local nephrology department. }\end{array}$ \\
& - Reuse RW from RO machines; \\
& - Use automatic dialysate flow regulators; \\
& - Use centrally delivered acid concentrated systems.
\end{tabular}

be the cornerstone of this action, setting improvement targets. Regular evaluation of the impact of implemented measures will guide further interventions. All members of staff should be involved in the green projects. Measures such as recycling waste materials should be implemented after adequate staff education (errors with recycling in potentially contaminated environments may pose a risk to public health).

National guidelines such as the Portuguese guidelines for chronic dialysis (Manual de Boas Práticas de Diálise Crónica da Ordem dos Médicos) should include ecological recommendations and targets in its next update.

Ecological criteria should be considered when institutions sign contracts with industry. New dialysis units and nephrology departments should be designed according to eco-friendly principles.

\section{CONCLUSION}

Kidney care is ecologically and economically onerous. Green nephrology projects have high innovative potential. Research in this field may combine clinical benefits with lowering environmental impact. Although some work has been done already, Portuguese nephrology can become greener.

\section{Acknowledgments}

Luis Libório; Elisabete Avelar Dias; José Pires; Sara Lobo; Elisabete Santos; Rita Reis; Cristina Lobo Oliveira; Célia Gil; Margarida Gonçalves; Sara Querido; André Weigert; Carlos Palma; José Augusto; Paulo Dinis; Pedro Ponce.

Disclosure of potential conflicts of interest: none declared.

\section{References}

1. Healthcare Without Harm. Healthcare's Climate Footprint. How the Heathcare Sector Contributes to Global Climate Crisis and Opportunities for Action. 2019.

2. Borg $M, B i$, Nitschke $M$, Williams $S$, McDonald $S$. The impact of daily temperature on renal disease incidence: an ecological study. Environmental Health. 2017 Oct 27;16(1).
3. Fakheri RJ, Goldfarb DS. Association of nephrolithiasis prevalence rates with ambient temperature in the United States: a re-analysis. Kidney International. 2009 Oct;76(7):798.

4. Glaser J, Lemery J, Rajagopalan B, Diaz HF, García-Trabanino R, Taduri G, et al. Climate Change and the Emergent Epidemic of CKD from Heat Stress in Rural Communities: The Case for Heat Stress Nephropathy. Clinical Journal of the American Society of Nephrology [Internet]. 2016 May 5 [cited 2019 Dec 25];11(8):1472-83.

5. Brikowski TH, Lotan Y, Pearle MS. Climate-related increase in the prevalence of urolithiasis in the United States. Proceedings of the National Academy of Sciences [Internet]. 2008 Jul 15 [cited 2020 Oct 20];105(28):9841-6.

6. Moura-Neto JA, Barraclough K, Agar JWM. A call-to-action for sustainability in dialysis in Brazil. Brazilian Journal of Nephrology. 2019 Dec;41(4):560-3.

7. Piccoli GB, Cupisti A, Aucella F, Regolisti G, Lomonte C, Ferraresi M, et al. Green nephrology and eco-dialysis: a position statement by the Italian Society of Nephrology. Journal of Nephrology. 2020 Apr 15;33(4):681-98.

8. Limb M. NHS could save 1 bn by adopting green strategies used in kidney units. BMJ. 2013 Jan 28;346(jan28 2):f588-8.

9. Mortimer F. Cumulative Savings from Green Nephrology Innovations. In: British Transplantation Society Congress. 2013.

10. Bikbov B, Purcell CA, Levey AS, Smith M, Abdoli A, Abebe M, et al. Global, regional, and national burden of chronic kidney disease, 1990-2017: a systematic analysis for the Global Burden of Disease Study 2017. The Lancet [Internet]. 2020 Feb;395(10225):709-33.

11. Galvão A, Filipe R, Leal R. Portuguese Registry of Dialysis and Transplantation. Portuguese Nephrology Society; 2019.

12. Connor A, Mortimer F, Tomson C. Clinical Transformation: The Key to Green Nephrology. Nephron Clinical Practice. 2010;116(3):c200-6.

13. Connor A, Lillywhite R, Cooke MW. The Carbon Footprints of Home and in-center Maintenance Hemodialysis in the United Kingdom. Hemodialysis International. 2011 Jan;15(1):39-51.

14. André Stragier, Jürgen Kastl, Jitka Pancirova, Al E. Enviromental guidelines for dialysis: a practical guide to reduce the enviromental burden of dialysis. Madrid [Casal García; 2011].

15. Hossain MdS, Santhanam A, Nik Norulaini NA, Omar AKM. Clinical solid waste management practices and its impact on human health and environment - A review. Waste Management. 2011 Apr;31(4):754-66.

16. Piccoli GB, Nazha M, Ferraresi M, Vigotti FN, Pereno A, Barbero S. Eco-dialysis: the financial and ecological costs of dialysis waste products: is a "cradle-to-cradle" model feasible for planetfriendly haemodialysis waste management?. Nephrology Dialysis Transplantation. $2015 \mathrm{Mar}$ 24;30(6):1018-27.

17. Hoenich NA, Levin R, Pearce C. Clinical Waste Generation from Renal Units: Implications and Solutions. Seminars in Dialysis. 2005 Sep 28;18(5):396-400.

18. Agar JWM. Green Dialysis: The Environmental Challenges Ahead. Seminars in Dialysis. 2014 Nov 30;28(2):186-92.

19. Molano-Triviño A, Wancjer B, Neri MM, Karopadi AN, Rosner M, Ronco C. Blue Planet dialysis: novel water-sparing strategies for reducing dialysate flow. The International Journal of Artificial Organs. 2017 Aug 11;41(1):3-10.

20. Tarrass F, Benjelloun M, Benjelloun $O$, Bensaha T. Water Conservation: an Emerging but Vital Issue in Hemodialysis Therapy. Blood Purif [Internet]. 2010;30:181-5.

21. Chang E, Lim JA, Low CL, Kassim A. Reuse of dialysis reverse osmosis reject water for aquaponics and horticulture. Journal of Nephrology. 2021 Jan 4;34(1):97-104.

22. Barraclough KA, Agar JWM. Green Nephrology. Nature Reviews Nephrology. 2020 Feb 7;16(5):25768.

23. Agar JWM. Reusing and Recycling Dialysis Reverse Osmosis System Reject Water. Kidney International. 2015 Oct;88(4):653-7.

24. Connor A, Milne S, Owen A, Boyle G, Mortimer F, Stevens P. Toward Greener Dialysis: a Case Study to Illustrate and Encourage the Salvage of Reject Water. Journal of Renal Care. 2010 Jun;36(2):6872 .

25. Albalate $M$, Pérez-García R, de Sequera P, Corchete E, Alcazar R, Ortega M, et al. Is It Useful to Increase Dialysate Flow Rate to Improve the Delivered Kt? BMC Nephrology. 2015 Feb 14 [cited 2020 Nov 19];16(1). 
26. Daugirdas JT, Blake PG, Ing TS, Al E. Handbook of Dialysis. Lippincott Williams \& Wilkins; 2015. 27. AGAR JW. Review: Understanding Sorbent Dialysis Systems. Nephrology. 2010 Mar 19;15(4):40611.

28. Gura V, Rivara MB, Bieber S, Munshi R, Smith NC, Linke L, et al. A Wearable Artificial Kidney for Patients with end-stage Renal Disease. JCl Insight. 2016 Jun 2;1(8).

29. van Gelder MK, Jong JAW, Folkertsma L, Guo Y, Blüchel C, Verhaar MC, et al. Urea Removal Strategies for Dialysate Regeneration in a Wearable Artificial Kidney. Biomaterials. 2020 Mar;234:119735.

30. Salani M, Roy S, Fissell WH. Innovations in Wearable and Implantable Artificial Kidneys. American Journal of Kidney Diseases. 2018 Nov;72(5):745-51.

31. Tarrass F, Benjelloun M, Benjelloun O. Recycling Wastewater after Hemodialysis: an Environmental Analysis for Alternative Water Sources in Arid Regions. American Journal of Kidney Diseases. 2008 Jul;52(1):154-8.

32. Machado CK, Pinto LH, Ciampo LFD, Lorenzi L, Correia CHG, Häder DP, et al. Potential Environmental Toxicity from Hemodialysis Effluent. Ecotoxicology and Environmental Safety. 2014 Apr;102:42-7.

33. General Directorate of Health, Disease Prevention and Health Promotion Directorate, Environmental Health Division. Hospital Waste (Practical Norm). 2008.

34. Ordem dos Médicos, Colégio da Especialidade de Nefrologia. Manual of Good Practice. 2017.

35. Blankestijn PJ, Bruchfeld A, Cozzolino M, Fliser D, Fouque D, Gansevoort R, et al. Nephrology: Achieving Sustainability. Nephrology Dialysis Transplantation. 2020 Sep 9;35(12):2030-3.

36. Agar JWM, Perkins A, Tjipto A. Solar-Assisted Hemodialysis. Clinical Journal of the American Society of Nephrology: CJASN [Internet]. 2012 Feb 1;7(2):310-4.
37. Cavaco A, Silva H, Canhoto P, Neves S. Radiação Solar Global em Portugal e a sua variabilidade. 2016

38. "Retro-Fit of Heat Exchangers to Haemodialysis Machines - Case Study and How to Guide Mapping Greener Healthcare." Available at sustainablehealthcare.org.uk/ east-kent-hospitals-universitynhs-trust/ retro-fit-heat-exchangers-haemodialysis-machines-case-study. 39. Accessed December 162020

39. James, R. "Dialysis and the environment: comparing home and unit-based hemodialysis" Journal of Renal Care, vol. 33, no. 3, 9 July 2007. 40.

40. Connor, Andrew, et al. "The Follow-up of Renal Transplant Recipients by Telephone Consultation: Three Years Experience from a Single UK Renal Unit." Clinical Medicine, 2011.

\section{Correspondence to:}

Diogo Francisco, MD

Serviço de Nefrologia e Transplantação Renal do Hospital de Santa Cruz, Centro Hospitalar Lisboa Ocidental

E-mail: diogofrbfrancisco@gmail.com 